enthusiasm and foresight of its curator, and the cost of its production, which must have been heavy, and which its council have so liberally borne. Inseparable from the great collections it elucidates, this book should attract workers to them. It furnishes the basis from which all future research on the morphology of the mammalian cerebrum that shall be exact must take its start.

\section{LIGHT FOR STUDENTS.}

Light for Students. By Edwin Edser, A.R.C.Sc., \&c. Pp. viii + 579. (London: Macmillan and Co., Ltd., I902.) Price $6 s$.

THIS book is intended to meet the wants of the same class of students as the author's "Heat for Advanced Students," published three years ago. It gives a comprehensive account of the phenomena and laws of geometrical and physical optics, with a number of simple, illustrative experiments and examination questions. Special pains have been taken throughout, as in the author's " Heat," to make all the explanations as simple as possible, so that the private student, who has not the advantage of a teacher's assistance in explaining his difficulties, should find the book particularly helpful. Advanced mathematical methods have been scrupulously avoided, and the calculus is rigidly excluded. This necessarily limits the scope of the work, but the author has found it possible to give a very good general idea of the more difficult parts of the subject and of comparatively advanced theories, such as Sellmeier's theory of dispersion, without making any extravagant demands on the mathematical knowledge of the student.

The first ten chapters are devoted to geometrical optics, the last ten to the development of the wave theory of light. A brief summary is given of the properties of thick lenses, as introducing an account of the eye and of vision through lenses and spectacles. In the chapter on optical instruments, the construction of eye-pieces is dealt with at unusual length, but on the other hand, the account of telescopes is somewhat scanty. Little or nothing is said about the conditions affecting the brightness of the image or the extent of the field of view. The ray diagrams are drawn, following the prevailing custom, without indicating the correct position of the eye. The diagram of Galileo's telescope shows a pencil of rays full and centrical on the object-glass, and small and excentrical on the eye-lens. This is the common practice in text-books, but it does not correctly represent the conditions of vision through this instrument.

The following experiment is given as a proof that the spherical aberration of the eye is over-corrected :-

"Expt. 35.-Close one eye, and place the other at a distance of less than ten inches from a printed page, so that the type cannot be clearly seen. Then place a pinhole immediately in front of the pupil. The printing will become clearly visible, although rendered fainter owing to the loss of light."

Simple experiments of this kind are very helpful to the student, but in this particular instance the conNO. I 737, VOL. 67] clusion is hardly justifiable. The pinhole would also make the print clearer if held near the margin of the pupil or if the print were beyond the distance of distinct vision of a short-sighted eye. The experiment would be more appropriate as an illustration of increased depth of focus produced by stopping down a lens. An adequate test of the spherical aberration of the eye is not quite so simple.

The wave theory of light is introduced by a chapter on vibrations and waves in general, including an elementary account of the propagation of transverse waves in an elastic solid. This is followed by a general explanation of the rectilinear propagation of light, and of the reflection and refraction of waves. The chapter on the spectrum contains many illustrations from astronomy, such as the proof of the nature of Saturn's rings derived from the Doppler effect. But no account is given of theories of colour vision or of experimental methods of investigation. The chapters on interference, diffraction and polarisation contain photographic illustrations by $\mathrm{Mr}$. W. B. Croft and others of fundamental phenomena. Some account is also given of recent instruments and experiments, such as the echelon grating and Rubens's experiments on infra-red rays of great wave-length. Limits of space have prevented the author from giving an account of the electromagnetic theory of light. The advisability of this would also have been questionable on other grounds. The book, considering its size, already contains an unusually large amount of information, and more could not reasonably be expected by the class of student for whom it is written.

H. L. C.

\section{OUR BOOK SHELF.}

Mr. Balfour's Apologelics Critically Examined. Pp. $\mathrm{vi}+232$. (London: Watts and Co., 1902.) Price 3s. $6 d$.

THIS book, issued anonymously by the Rationalist Press Association, is explicitly directed against Mr. Balfour's defence of Christianity (p. 10). To those who read with an animus against this "decaying creed," the author's vigour and lavish use of epithets may appear conclusive reasoning. To the impartial, it will scarcely appear to be criticism at all. Mr. Balfour's method in the "Foundations of Belief" was to advance from the more general philosophic position to the problem of "Pro. visional Unification." However much his critic believed that Mr. Balfour's theism was based on "emotion and sentiment"(p. 222), or that it could be explained by a review of his pedigree (p. 224), he had no right to rely too much on this application of the historical method.

At least, one expects to find that the "frontal attack" which the author prefers to Mr. Balfour's "sap and mine" (p. 222) shall be directed against the real strong. hold. Yet, so far as this book goes, the author leaves untouched the questions, Has experience any elements which cannot be treated as we treat knowledge of "things"? If so, do these elements constitute data from which we may infer that "the whole circuit of belief" has wider foundations than "science" as such requires? And lastly, if the foundations are thus widened, do they admit Theism or Christianity as a form of it? It is easy to call the Incarnation a manifest absurdity; what is 